\title{
Severe Vascular Complications Following Thrombolytic Therapy in a Case of Prosthetic Mitral Valve Thrombosis - A Case Report
}

\author{
Ayan Husain ${ }^{1}$, Shilpa Abhay Gaidhane 2 , Priti Abhay Karadbhajane ${ }^{3}$, Sourya Acharya ${ }^{4}$, Apoorva Nirmal ${ }^{5}$
}

1, 2,3,4,5 Department of Medicine, Jawaharlal Nehru Medical College, DMIMS

(Deemed to Be University), Sawangi (Meghe), Wardha, Maharashtra, India.

\section{INTRODUCTION}

Prosthetic cardiac valve thrombosis is a rare but dangerous complication;1,2 particularly in patients with low conformity on anticoagulant therapy. Thromboembolic problems happen after mechanical valve substitution in $0.5-8$ percent. ${ }^{3-5}$ Fibrinolytic therapy to treat the thrombosis is widely used nowadays with high efficacy and no severe side effects as compared to emergency surgical treatment, which is associated with high mortality. ${ }^{6}$

Surgical valve repair in patients with rheumatic heart disease remains the gold standard for the treatment. Thrombosis of the prosthetic heart valve in patients undergoing valve replacement, is the most severe and deadly complication. Currently, the treatments available for symptomatic prosthetic valve thrombosis are immediate surgery or thrombolytic therapy (TT). In rural hospital settings patients are poor and there is a lack of surgical expertise. These factors make TT the perfect treatment for prosthetic valve thrombosis. But one should be aware of embolic complications.

\section{PRESENTATION OF CASE}

A 30-year-old male patient a known case of rheumatic heart disease with severe mitral stenosis underwent mitral valve replacement with TTK Chitra mitral prosthesis in 2017. Two years later, he presented to the Emergency Department of Medicine at night $8 \mathrm{pm}$ with complaints of, sudden onset of breathlessness, chest pain and orthopnoea for 24 hours. He had stopped taking anticoagulants a month back due to financial constraints.

On examination, heart rate - 115 / $\mathrm{min}, \mathrm{BP}-86$ / $50 \mathrm{mmHg}$, jugular venous pressure (JVP) raised. Metallic click could not be heard, bilateral crepitations present. Electrocardiogram-atrial fibrillation (ECG-AF) with FVR with right ventricular hypertrophy. Haemoglobin (Hb) - 14.6 g / dl, white blood cell (WBC) - 13900 / mm, ${ }^{3}$ platelets - 1.56 lac / mm, ${ }^{3}$ creatinine - 1.1, liver function test (LFT) normal and international normalised ratio (INR) 1.08. Blood cultures showed no growth of any organisms. Clinical diagnosis of a thrombotic mitral valve thrombosis was confirmed by transthoracic echocardiography. The effective valve area was $0.45 \mathrm{~cm}^{2}$ with evidence of $1 \mathrm{~cm}^{2}$ thrombus and an increased mean peak gradient $(23 \mathrm{mmHg})$ across the mitral valve (Figure 1).
Corresponding Author: Dr. Shilpa Gaidhane,

Department of Medicine,

Jawaharlal Nehru Medical College, DMIMS (Deemed to Be University), Sawangi (Meghe), Wardha,

Maharashtra, India.

E-mail: drshilpagaidhane@gmail.com

DOI: $10.14260 /$ jemds/2021/221

How to Cite This Article:

Husain A, Gaidhane SA, Karadbhajane PA, et al. Severe vascular complications following thrombolytic therapy in a case of prosthetic mitral valve thrombosis - a case report.. J Evolution Med Dent Sci 2021;10(14):1035-1038, DOI: 10.14260/jemds/2021/221

Submission 02-11-2020,

Peer Review 11-02-2021,

Acceptance 17-02-2021,

Published 05-04-2021.

Copyright (c) 2021 JEMDS. This is an open access article distributed under Creative Commons Attribution License [Attribution 4.0 International (CC BY 4.0)] 

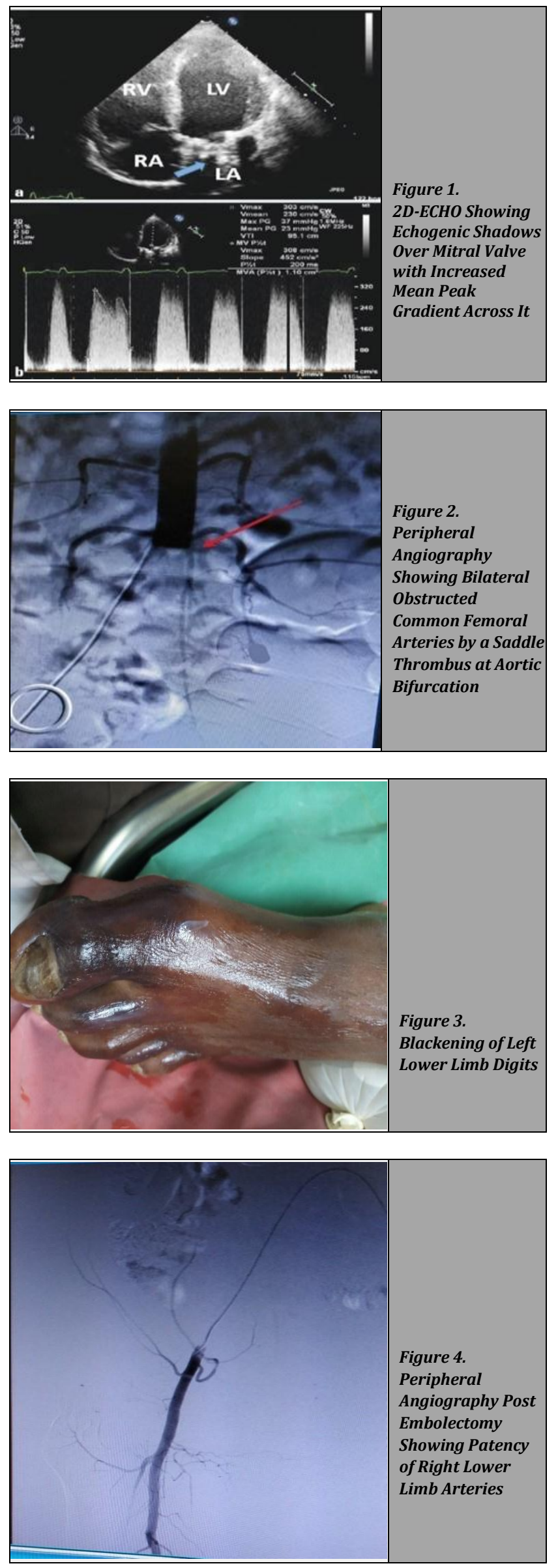

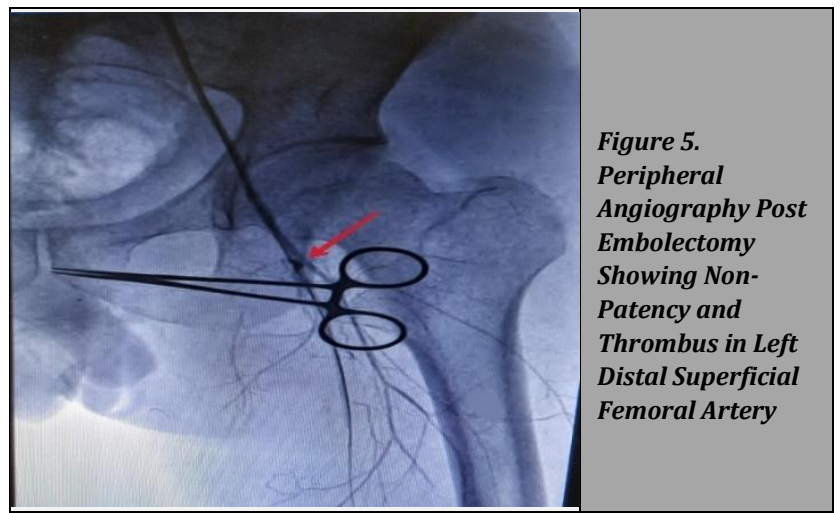

Therefore, dobutamine along with furosemide were infused continuously for cardiogenic shock and acute pulmonary oedema, and intravenous diltiazem was given for heart rate control. Fibrinolytic therapy with streptokinase was given because of the unavailability of vascular surgeon at the time of presentation. Within 3 hours after the start of therapy the patient's symptoms of heart failure had improved markedly but he developed pain and weakness of both lower limbs, more in left side as compared to right side. Peripheral pulsations could not be palpated in both the lower limbs below the femoral artery. 2D-ECHO post thrombolysis-good leaflet motion of mitral valve and peak gradient of $8 \mathrm{mmHg}$ across the valve with no thrombus or vegetation. The calculated mitral valve area increased to $1.65 \mathrm{~cm}^{2}$ Bilateral lower limb angiography was done immediately which showed saddle thrombus at aortic bifurcation. (Figure 2) with slow reformation of bilateral iliac arteries. Thrombectomy was done by the vascular surgeon at our institute and parenteral anticoagulants were started.

After three days, right lower limb symptoms resolved. But only partial relief of symptoms in left lower limb and there was left sided foot drop after 5 - 6 days, the patient started developing blackening of left lower limbs digits without any clear-cut line of demarcation. (Figure 3). Check angiography revealed no saddle thrombus at aortic bifurcation, good distal flow in right common iliac artery and below (Figure 4) but there was long segment subacute thrombus in left distal superficial femoral artery (Figure 5). There was no gangrene and the pain decreased. Patient was managed conservatively, and he was discharged on oral anticoagulants, antiplatelets and analgesics. Followed up with us one month later. The blackening of digits had recovered. Doppler showed partial thrombotic narrowing of superficial femoral artery with good collateral circulation.

\begin{tabular}{|c|c|c|}
\hline Factors Deciding & Thrombolytic Therapy & Surgery \\
\hline Clinical features & $\begin{array}{l}\text { High surgical risk, NYHA class } \\
\text { i to ii, no contraindication to } \\
\text { fibrinolysis, first episode of } \\
\text { valve thrombosis }\end{array}$ & $\begin{array}{l}\text { Low surgical risk, NYHA class } \\
\text { III to IV, contraindication to } \\
\text { fibrinolysis, recurrent valve } \\
\text { thrombosis }\end{array}$ \\
\hline $\begin{array}{l}\text { Concurrent } \\
\text { indications }\end{array}$ & $\begin{array}{l}\text { No need for other cardiac } \\
\text { surgery such as CABG or other } \\
\text { valve disease }\end{array}$ & $\begin{array}{l}\text { Coronary artery disease } \\
\text { needing CABG, concomitant } \\
\text { valve or aortic disease } \\
\text { requiring surgery }\end{array}$ \\
\hline Imaging findings & $\begin{array}{l}\text { Thrombus or small clot }(<1 \\
\left.\mathrm{cm}^{2}\right) \text {, no left atrial thrombus }\end{array}$ & $\begin{array}{l}\text { Large clot }\left(>1 \mathrm{~cm}^{2}\right) \text {, mobile } \\
\text { thrombus }>0.3 \mathrm{~cm} \text { in diameter, } \\
\text { or left atrial thrombus }\end{array}$ \\
\hline Resources & No surgical expertise required & Surgical expertise is required \\
\hline \multicolumn{3}{|c|}{ Table 1. Factors Deciding Thrombotic Therapy vs. Surgery } \\
\hline
\end{tabular}




\section{DISCUSSION OF MANAGEMENT}

Prosthetic valve thrombosis (PVT) is a very serious complication after valve replacement. Factors predisposing to thrombosis include atrial fibrillation, sub-therapeutic anticoagulation and irregular INR monitoring, and pregnancy. Mitral valve is approximately twice as commonly involved as aortic valve.1,2 The most common complications of PVT are valvular obstruction or stenosis and thromboembolism. The reported incidence of symptomatic obstructive mechanical PVT ranges from 0.2 to $8 \%$ per year in India and it is more common (6\%) in patients receiving sub-therapeutic anticoagulation..$^{3-5}$ The rate of thromboembolism after PVT during the first 6 months is significantly more and it is highest during the first 30 days. ${ }^{6-8}$ The risk of thromboembolism is least in patients with bio-prosthetic valves (who are generally not anti-coagulated), higher with patients of mechanical valves who are anticoagulated and highest in patients of mechanical valves receiving inadequate anti-coagulation. ${ }^{9}$ High mortality and morbidity are associated with prosthetic valve thrombosis. ${ }^{10}$

Prosthetic valve thrombosis has been split into two forms: obstructive (embolus of more than $10 \mathrm{~mm}^{2}$ ) and nonobstructive (embolus of less than $10 \mathrm{~mm}^{2}$ ) prosthetic valve thrombosis and their therapeutic approach. ${ }^{10}$

Valvular obstruction may present with heart failure, presyncope or syncope and in rare cases sudden cardiac death. Left sided PVT may cause systemic embolic complications such as stroke, peripheral gangrene or less frequently myocardial infarction. Right sided PVT can complicate into pulmonary embolism and rarely systemic embolic events via paradoxical embolism. ${ }^{11}$

The diagnostic criteria on echo cardiac for PVT are decreased valve strength, mass over the valve (thrombus), decreased effective prosthetic area, and trans prosthetic valve flow, prosthetic valve incompetence, increased transprosthetic gradients. ${ }^{12}$ Treatment modality depends on i) existence of distortion of the valve, ii) Medical status of the patient, iii) the thrombus size, iv) The local level of medicine and economy, and $v$ ) the experience with reoperation. Hospitals that do not have practice with reoperation or location of financially poor regions have a high surgical cost, making TT the perfect treatment for PVT. ${ }^{13}$

Mechanical PVT is managed mainly by fibrinolysis or by surgery (thrombectomy and valve replacement) along with supportive treatment of heart failure and anticoagulation with unfractionated heparin (Table 1). ${ }^{1}$ In our case thrombolysis was preferred due to high New York Heart Association (NYHA) Class, and un-availability of surgeon and expertise with reopening in emergency hours. We ruled out the contraindications for thrombolysis ${ }^{1}$. There was uncontrolled blood pressure hypertension above 180 / $110 \mathrm{mmHg}$; ischaemic stroke or cerebral haemorrhage within half a year; intracranial tumour; active internal bleeding in the last 4 weeks; possible aortic dissection; past of previous 3 weeks for major surgery; 2 week's large uncompressible artery puncture; antenatal status; active stomach ulcers; and history of major surgery in the last 3 weeks, patients with a thrombus size $>1 \mathrm{~cm}^{2}$ or a high density of thrombi were also excluded. ${ }^{13}$ Recently, as the first-line treatment plan for class 1-B indications, the 2017 American Heart Association (AHA)/ American College of Cardiology (ACC), based update of the 2014 AHA / ACC instruction for the treatment of patients with valvular heart disease advised using slow-infusion low-dose TT or immediate surgery for obstructive PVT. ${ }^{14}$

Complications of thrombolysis in PVT include major bleeding intracerebral, systemic embolism, recurrent PVT, and death. ${ }^{15,16}$ Surgery is recommended for vital surgery for obstructive thrombosis (thrombus more than one $\mathrm{cm}^{2}$ ) or fibrinolytic therapy for non-obstructive PVT (approximately $10 \mathrm{~mm}){ }^{15}$ In seven PVT thrombolysis trials, Karthikeyan tested 690 patients and observed no substantial contrast in main results (development in gradient transvalvular pressure and severe problems) between surgery and thrombolysis. They indicated, however, that an immediate surgical operation is preferable to TT in an experienced centre. ${ }^{12}$ Previous data revealed that 69 percent death rate for surgery was higher compared with this meta-analysis, while the recorded mortality rate for TT was as high as 16 percent, relying on the NYHA grade and the priority of the surgery. 13 Therefore, suitability of surgical treatment is not for all patients. In a meta-analysis by Cáceres-Lórigal recorded 4.6 to 12.8 percent rate of embolism complications from nine studies of 413 patients ${ }^{13}$

Major risk factors for complications of thrombolysis include NYHA class III or IV and a large thrombus. The risk of systemic embolism, bleeding and death are the complications of high-dose fibrinolytic therapies. Bleeding during fibrinolysis is rare in the absence of bleeding conditions like pregnancy, postoperative, or pericarditis. ${ }^{14}$

Maintenance of anticoagulation therapy with INR monitoring is the corner stone for prevention of thrombus formation among patients with prosthetic valve replacement. ${ }^{21}$ More efforts are need for patient education and drug adherence of anticoagulation therapy. ${ }^{22}$

\section{CONCLUSIONS}

Thrombolysis for prosthetic valve thrombosis is a good alternative to surgery in selected patients at a tertiary care hospital without emergency facility of vascular-surgical and Cath lab facility. Physicians should be aware of embolic complications to manage them successfully. Adherence to anticoagulants and monitoring of INR is the key to prevent prosthetic valve thrombosis.

Financial or other competing interests: None.

Disclosure forms provided by the authors are available with the full text of this article at jemds.com.

\section{REFERENCES}

[1] Roudaut R, Serri K, Lafitte S. Thrombosis of prosthetic heart valves: diagnosis and therapeutic considerations. Heart 2007;93(1):137-42.

[2] Cannegieter SC, Rosendaal FR, Briet E. Thromboembolic and bleeding complications in patients with mechanical heart valve prostheses. Circulation 1994;89(2):635-41. 
[3] Inamdar A, Shende SP, Inamdar S. Prosthetic valve obstruction: redo surgery or fibrinolysis? Medical Journal of Dr. DY Patil University 2017;10(3):246-50.

[4] Kearon C, Akl EA, Comerota AJ, et al. Antithrombotic therapy for VTE disease: antithrombotic therapy and prevention of thrombosis, 9th edn: American College of Chest Physicians Evidence-Based Clinical Practice Guidelines. Chest 2012;141(Suppl 2):e419S-96S.

[5] Dürrleman N, Pellerin M, Bouchard D, et al. Prosthetic valve thrombosis: twenty-year experience at the montreal heart institute. J Thorac Cardiovasc Surg 2004;127(5):1388-92.

[6] Deviri E, Sareli P, Wisenbaugh T, et al. Obstruction of mechanical heart valve prostheses: clinical aspects and surgical management. J Am Coll Cardiol 1991;17(3):64650.

[7] Puvimanasinghe JP, Steyerberg EW, Takkenberg JJ, et al. Prognosis after aortic valve replacement with a bioprosthesis: predictions based on meta-analysis and microsimulation. Circulation 2001;103(11):1535-41.

[8] Remadi JP, Baron O, Roussel C, et al. Isolated mitral valve replacement with St. Jude Medical prosthesis: long-term results: a follow-up of 19 years. Circulation 2001;103(11):1542-5.

[9] Le Tourneau $\mathrm{T}$, Lim $\mathrm{V}$, Inamo J, et al. Achieved anticoagulation vs prosthesis selection for mitral mechanical valve replacement: a population-based outcome study. Chest 2009;136(6):1503-13.

[10] Karakurt A, Başbuğ HS. Prosthetic heart valve thrombosis treated with low-dose slow-infusion fibrinolytic therapy. J Cardiol Cases 2015;12(1):12-5.

[11] Faria DC, Roque D, Santos M, et al. Obstructive mechanical mitral valve thrombosis: a case report. Annals of Clinical Case Reports 2019;4;1655.

[12] Karthikeyan G, Senguttuvan NB, Joseph J, et al. Urgent surgery compared with fibrinolytic therapy for the treatment of left-sided prosthetic heart valve thrombosis: a systematic review and meta-analysis of observational studies. Eur Heart J 2013;34(21):1557-66.
[13] Cáceres-Lóriga FM, Morais H. Thrombotic obstruction in left-side prosthetic valves: role of thrombolytic therapy. Indian Heart J 2015;67(Suppl 2):S10-2.

[14] Matiasz R, Rigolin VH. 2017 Focused update for management of patients with valvular heart disease: summary of new recommendations. Journal of the American Heart Association 2018;7(1):e007596.

[15] Roudaut R, Lafitte S, Roudaut MF, et al. Fibrinolysis of mechanical prosthetic valve thrombosis: a single-center study of 127 cases. J Am Coll Cardiol 2003;41(4):653-8.

[16] Huang G, Schaff HV, Sundt TM, et al. Treatment of obstructive thrombosed prosthetic heart valve. J Am Coll Cardiol 2013;62(19):1731-6.

[17] Srivastava R, Showkat HI, Kumar V, et al. An interesting case of stuck mitral valve by clot, post thrombolysis developed acute right limb ischemia treated with local catheter directed re-thrombolysis successfully. Int J Cardiol Cardiovasc Res 2018;4(2):085-8.

[18] Hirschl MM, Gwechenberger $M$, Zehetgruber $M$, et al. Severe complications following thrombolytic therapy of an acute thrombosis of a prosthetic mitral valve. Clin Investig 1994;72(6):466-9.

[19] Bagheri RK, Keihanian F, Ahmadi M, et al. Successful treatment of prosthetic pulmonary valve thrombosis with reteplase: a case report. Int Med Case Rep J 2018;11:2058.

[20] Shi J, Bai ZX, Hu J, et al. Rare early prosthesis obstruction after mitral valve replacement: a case report and literature review. J Cardiothorac Surg 2012;7:64.

[21] Gazi E, Altun B, Temiz A, et al. Successful thrombolytic treatment of prosthetic mitral valve thrombosis. BMJ Case Rep 2013;2013:bcr2013009917.

[22] Özkan M, Çakal B, Karakoyun S, et al. Thrombolytic therapy for the treatment of prosthetic heart valve thrombosis in pregnancy with low-dose, slow infusion of tissue-type plasminogen activator. Circulation 2013;128(5):532-40. 